\title{
COMPARATIVE EVALUATION OF OCULOMETRIC VARIABLES IN GRAVES' OPHTHALMOPATHY
}

\author{
Hélio Amante Miot, ${ }^{\mathrm{I}}$ Leonardo Parr dos Santos Fernandes, ${ }^{\mathrm{II}}$ Edson Nassib

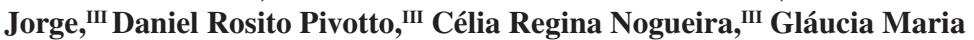 \\ Ferreira da Silva Mazeto ${ }^{\mathrm{II}}$
}

doi: $10.1590 / \mathbf{S 1 8 0 7 - 5 9 3 2 2 0 0 9 0 0 0 9 0 0 0 0 9}$

\begin{abstract}
Miot HA, Fernandes LPS, Jorge EN, Pivotto DR, Nogueira CR, Mazeto GMFS. Comparative evaluation of oculometric variables in graves' ophthalmopathy. Clinics. 2009;64(9):885-9.
\end{abstract}

OBJECTIVES: To estimate oculometric parameters of Graves' ophthalmopathy in comparison to healthy eyes using digital photography and digital image analysis.

INTRODUCTION: Graves' ophthalmopathy is the main cause of eye proptosis. Because these protrusions cause clinically perceived distortions in orbital architecture, digital photographs can be used to detect and quantify these changes.

METHODS: We carried out a cross-sectional study comprising 12 healthy volunteers and 15 Graves' ophthalmopathy patients with the purpose of evaluating the use of simple, non-invasive digital photography to estimate oculometric parameters of Graves' ophthalmopathy and compare them with the parameters of unaffected eyes.

Facial photographs of cases and controls were taken in a standardized manner. Oculometric parameters were compared between the groups and then correlated to proptometer measures.

RESULTS: All estimated oculometric variables showed significant differences between the groups, in particular with regard to mediopupilar aperture, lateral height, distance from the iris edge to the lateral boundary of the palpebral fissure, and distance from the higher point of the iris to the lateral limit of the palpebral fissure. The product of medial aperture and horizontal palpebral fissure also revealed greater discrepancy between the groups. Proptometer measures showed significant linear correlation between the distance from the iris edge to the lateral boundary of the palpebral fissure and between the distance from the higher point of the iris to the lateral limit of palpebral fissure $(\mathrm{p}<0.05)$.

CONCLUSIONS: Comparative analysis of oculometric parameters in Graves' ophthalmopathy suggests that eye proptosis is related to an asymmetric increase in lateral oculometric measures. Standardized digital photographs can be used in clinical practice to objectively estimate oculometric parameters of Graves' ophthalmopathy patients.

KEYWORDS: Biometry; Eye abnormalities; Graves' disease; Graves'; Ophthalmopathy; Photography.

\section{INTRODUCTION}

Graves' ophthalmopathy (GO), or thyroid ophthalmopathy, is an autoimmune condition that primarily affects extraocular muscles and occurs in more than $90 \%$ of patients

\footnotetext{
I Dermathology Department, Botucatu Medical School, São Paulo State University (UNESP) - Botucatu/SP, Brazil.

II Internal Medicine Department, University of Marília - Marília/SP, Brazil. III Ophthalmology Department, Botucatu Medical School, São Paulo State University (UNESP) - Botucatu/SP, Brazil.

Email: gmazeto@fmb.unesp.br

Tel: 55143811.6213

Received for publication on February 26, 2009

Accepted for publication on June 30, 2009
}

with Graves' disease. Despite this prevalence, just 3 to $4 \%$ of these patients evolve to visual damage. ${ }^{1-3}$

This ophthalmopathy is currently recognized as the most common cause of proptosis in adults, causing distress due to functional impairment and a cosmetically unacceptable appearance. In addition, ocular pain, diplopia, compressive optic neuropathy, and exposure keratopathy can also occur. ${ }^{2,4}$

The physiopathology seems to be an autoimmune reaction against orbital fibroblasts. The immune response targets extraocular muscles, orbital fat and the lacrimal gland. Stimulation of orbital fibroblasts in these tissues causes the production of hyaluronic acid, which increases the osmotic load of the tissues and results in passive swelling. ${ }^{1}$ 
Despite its frequency and the ease of diagnosis, ${ }^{5}$ treatments are currently unsatisfactory. GO is usually estimated by the severity of clinical symptoms, orbital ultrasonography, computed tomography scanning, magnetic resonance imaging, or proptometry. ${ }^{4-8}$ Few studies have evaluated oculometric changes in GO, and there is some difficulty in estimating slight clinical improvements in clinical or experimental trials. This difficulty is mainly caused by the low sensitivity, low reproducibility, and high costs of each method for GO estimation. .11 $^{-11}$

Because proptosis causes clinically perceived distortions in orbital architecture, digital photographs can also be used to detect and quantify these changes in ocular measurements.

Digital photography is a bidimensional modality of image recording where the complexity of light is represented as a pixel matrix of fixed and known location values and color intensity. ${ }^{12}$

We propose the use of simple and non-invasive digital photography and digital image analysis to estimate oculometric parameters of GO.

\section{SUBJECTS AND METHODS}

A total of 24 eyes (12 volunteers) without clinical and laboratorial evidence of thyroid disease or GO and 30 eyes (15 patients) with GO were photographed.

Cases were selected among current Graves' disease patients from Botucatu Medical School, Sao Paulo State University. Normal controls were chosen from the hospital healthcare staff and were paired by age.

GO was diagnosed after clinical evaluation. Inclusion criteria were: moderate and severe bilateral ocular involvement (class 2, grade c; class 3, grades a-c; class 4, grades a-c; class 6 , grade a), according to the "NO SPECS" classification. ${ }^{7}$ Soft-tissue involvement and eye disease activity were defined according to a Clinical Activity Score (CAS) of three or more. ${ }^{6,8}$

Exclusion criteria were: self-referred Asian or AfricanAmerican ethnic group, use of contact lenses, and history of orbital tumors, trauma or scars.

Digital photographs were taken at a standardized distance, framing the face centrally, with the gaze lasting a few seconds, using a digital camera (Sony Cybershot DSC P32, $\mathrm{f}=1 / 2.8,1632 \times 1224$ pixels of resolution, RGB 24 bits, ISO 100). Images were then saved as JPEG files. Digital photographs were taken at a $60-\mathrm{cm}$ distance from the patients, by the same photographer and in the same room. The camera was positioned at eye-height, under the same artificial fluorescent lighting.

The images were analyzed in ImageJ $1.41 \mathrm{v}$ software. Oculometric variables (Figure 1), such as MAR

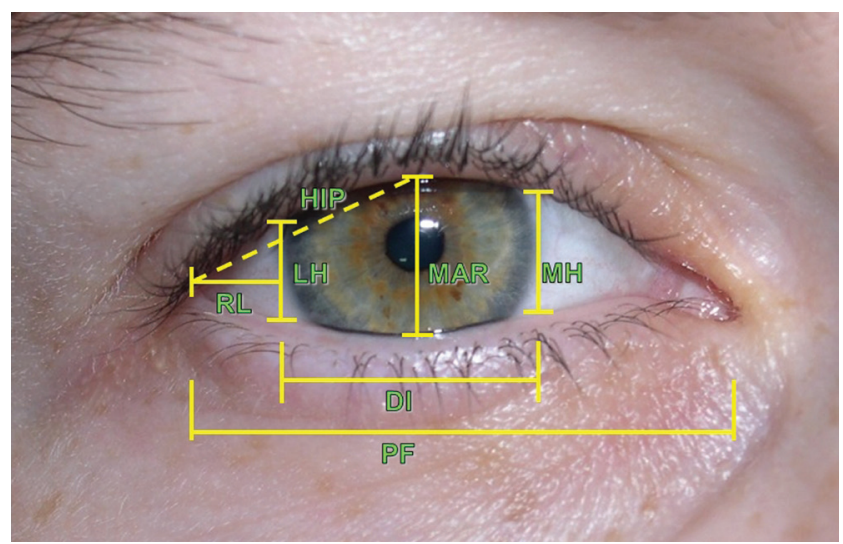

Figure 1 - Standardized eye measures: DI (horizontal diameter of the iris); MAR (mediopupilar aperture); $\mathrm{PF}$ (horizontal palpebral fissure); MH (medial aperture height, tangential to iris); LH (lateral aperture height, tangential to iris); RL (distance of iris edge to the lateral boundary of palpebral fissure); and HIP (distance from the highest point of iris to the lateral limit of the palpebral fissure)

(mediopupilar aperture), PF (horizontal palpebral fissure), MH (medial aperture height, tangential to iris), LH (lateral aperture height, tangential to iris), RL (distance of iris edge to the lateral boundary of palpebral fissure), and HIP (distance from the highest point of iris to the lateral limit of the palpebral fissure), were calculated according to the size in pixels of each structure. The lengths were expressed according to individual horizontal iris diameter (DI). ${ }^{13,14}$ Secondary variables were also calculated: lateral-medial aperture ratio $(\mathrm{L} / \mathrm{M})$ and product of medial aperture and palpebral fissure (MAxPF). The author who analyzed the pictures was not aware of the match between eyes and study groups, although there was clear visual evidence of GO in every patient with the disease.

Proptosis of each eye was also assessed by proptometer (Exophthalmometer of Marco; Marco Ophthalmic Co, EUA) and measured in millimeters ( $\mathrm{mm}$ ).

Oculometric parameters were compared between the groups and then correlated to proptometer measures.

The normality of the measured variables was assessed by the Shapiro-Wilk test. Central tendency measures were expressed as mean and median, while dispersion measures were standard deviation (SD), variance, interquartile range (IQR). Correlation measures were estimated by Pearsons' correlation test after best-fit curve adjustment. Betweensample comparisons were done by Student's t-test or MannWhitney test (if indicated). Comparisons between methods were performed by paired Student's t-test. The statistical analysis was performed using Bioestat 5.0 software, and twotailed p-values less than 0.05 were considered as significant. ${ }^{15}$

Sample size was evaluated after a pre-test comprising $24 \mathrm{GO}$ and 30 unaffected eyes, considering comparison of oculometric means with the goal of reaching a minimum 
difference of $20 \%$, according to a power of 0.85 and bilateral alpha significance level of 0.01 .

This work was approved by the Unesp ethical committee for human research (process 1179/2003).

\section{RESULTS}

Baseline epidemiologic data from two groups showed no statistical differences with regard to gender, age and thyroid hormonal parameters (free T4 and TSH) because GO patients were under adequate treatment (Table 1). Thyroid autoantibodies were detected only in GO patients. The mean ( \pm standard deviation) proptometer measurements were $21.9 \pm 1.7 \mathrm{~mm}$ and $16.8 \pm 1.7 \mathrm{~mm}$ in $\mathrm{GO}$ and volunteers, respectively $(\mathrm{p}<0.01)$.

Table 1 - Baseline clinical and epidemiologic data from the study participants

\begin{tabular}{|c|c|c|c|}
\hline & GO patients & $\begin{array}{c}\text { Non-GO } \\
\text { volunteers }\end{array}$ & $\mathrm{p}$ \\
\hline \multicolumn{4}{|l|}{ Sex: } \\
\hline Females & 11 & 9 & $0.63^{*}$ \\
\hline Males & 4 & 3 & \\
\hline \multicolumn{4}{|l|}{ Age (in years) } \\
\hline Median & 36 & 30 & $0.64^{* *}$ \\
\hline $\mathrm{IQR}^{\Delta}$ & 9.5 & 24 & \\
\hline \multicolumn{4}{|l|}{ Current thyroid parameters } \\
\hline fT4 $\left(\right.$ median $\pm \mathrm{IQR}^{\Delta}$ ) & $1.45 \pm 0.4$ & $1.43 \pm 0.2$ & $0.45^{* *}$ \\
\hline $\mathrm{TSH}\left(\right.$ median $\left.\pm \mathrm{IQR}^{\Delta}\right)$ & $0.9 \pm 1.6$ & $1.6 \pm 0.8$ & $0.10^{* *}$ \\
\hline $\mathrm{TPO}-\mathrm{Ab}^{\dagger}$ positive $\mathrm{N}(\%)$ & $11(66.7)$ & - & $<0.01^{*}$ \\
\hline TG-Ab positive $\mathrm{N}(\%)$ & $8(53.3)$ & - & $<0.01^{*}$ \\
\hline Proptosis in mm (mean $\pm \mathrm{sd})$ & $21.9 \pm 1.7$ & $16.8 \pm 1.7$ & $<0.01^{* * * *}$ \\
\hline
\end{tabular}

Right and left eyes were correlated with regard to proptometer measures in both groups, with a Pearson's $\mathrm{R}=0.81$ and 0.93 for the $\mathrm{GO}$ and control groups, respectively $(\mathrm{p}<0.01)$.

All oculometric variables estimated showed significant differences between the groups, but MAR, LH, RL, HIP and MAxPF disclosed the greatest discrepancies (Figure 2).

Proptometer measures showed slight but significant logarithmic correlation to RL and HIP ( $\mathrm{R}=0.33$ and 0.35 , $\mathrm{p}<0.05$ ). These variables estimate lateral asymmetric eye displacement.

There was no difference in the frequencies of inferior "scleral show" between the groups, nor was this parameter correlated to proptometry $(\mathrm{p}>0.1)$.

\section{DISCUSSION}

Computational image editors can display and analyze

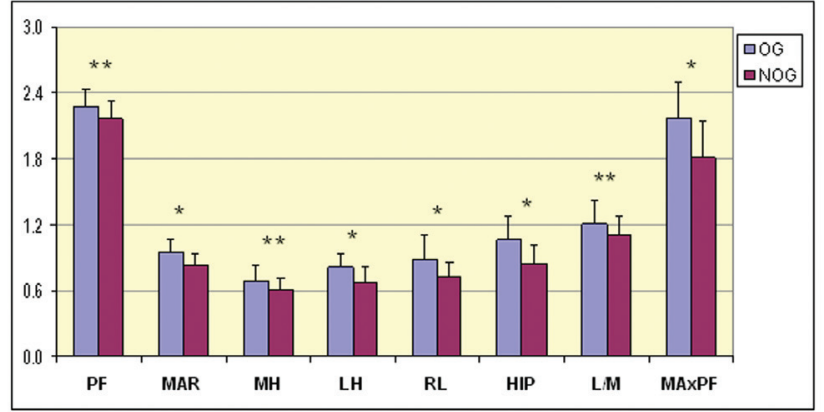

Figure 2 - Comparison of eye measures between GO and non-GO patients adjusted to iris diameter (mean \pm standard deviation)

digital images, and digital image pixels can be quantified and measured. These properties allow the use of digital image analysis systems to estimate length, morphology, color intensity and texture in several fields of science. ${ }^{16,17}$

GO promotes severe alterations in the entire orbital structure and often requires assessment using invasive and expensive techniques (e.g., computerized tomography). On the other hand, digital photography can only estimate external ocular modifications. Despite this limitation, this study discloses several differences between controls and GO patients that can be observed with digital photography. Therefore, noninvasive standardized digital photographs allow reliable ocular documentation and clinical assessment in GO, with regard to orbital changes. The effective measurement of oculometric parameters could lead to an objective estimation of the effects of therapeutic interventions. ${ }^{11,18}$

In this study, we evaluated oculometric variables that can quantify abnormalities in GO patients through the use of digital standardized photographs. Despite individualities of ocular involvement, proptosis modifies the architecture of the whole eye, and the outer projection can be assessed by digital measures, especially lateral variables such as $\mathrm{LH}$, RL, HIP and MAxPF.

General oculometric measures revealed drastic differences between normal and GO eyes as assessed by digital photography, despite the slight correlation to proptometry. These findings suggest that digital photography morphometry can identify minor ocular alterations, in a more sensitive way than the proptometer itself.

Despite high correlation, there are some minor discrepancies between left and right proptosis in both groups, but mainly in the GO group. The analysis of each eye individually, instead of through patient-by-patient analysis, reduces the influence of these asymmetries in the comparison among groups.

Comparing the eyelid contour of GO, blepharoptosis and normal eyes, Cruz et al. found that GO caused increased 
curvature of the upper eyelid, mostly in the temporal upper quadrant, reinforcing our findings of enhanced lateral oculometric measures. ${ }^{11}$ Although eyelid retraction is universally characterized by fissure central height, our results showed that this measure is not the major feature in $\mathrm{GO}$ because a laterally asymmetrical pattern of eyelid retraction was observed.

Reliability of the method depends on careful photographic standardization as well as eye positioning and eyelid tension. When performing clinical or experimental trials, the increase in sample size, the number of pictures per eye, or even the use of a video camera for selecting the more representative picture can reduce any interference with accurate measurements. ${ }^{11,19,20}$

Careful standardization of light, framing, zoom and position remains the key factor for accurate orbital and eye measurements. Photographic measures usually employ a transparent ruler lined up to the visual axis for index measures. ${ }^{21}$ Miot et al. demonstrated that these measures were highly correlated to oculometric estimation as indexed by individual iris diameter, enabling comparative oculometric evaluations both in clinical practice and research through the use of a widely available technology. ${ }^{14}$

Patients with uncontrolled thyroid function (both hyperand hypothyroidism) are more likely to evolve to severe GO than patients with euthyroidism. ${ }^{3}$ In this study, TSH and fT4 blood levels were similar in both GO and control patients, excluding the influence of thyrotoxicosis and sympathetic tonus affecting oculometric changes.

The low cost, availability, non-invasiveness, ability to "blind" the examiner, and the ease of transfer and display make digital photography a suitable method for clinical documentation and even clinical trials. Digital photographs can also be easily stored and re-employed in future studies. Likewise, old pictures, since a minimum standardization has been observed, can be analyzed by this method, in spite of the absence of metric scales. This study has indexed oculometric measures based on individual iris diameter, an invariable and highly reproducible index even for different distances between the camera and the patient, as well as stored pictures. ${ }^{14}$

This preliminary study excluded asymmetric GO and patients with tumors, scars and other ocular pathologies because any of those complications could cause orbital architecture distortions and alter external eye measures, representing limitations to this study.

Finally, the comparative analysis of oculometric parameters in Graves' ophthalmopathy suggests that eye proptosis is related to an asymmetric increase in lateral oculometric measures. The results suggest that standardized digital photographs can be used to objectively estimate oculometric parameters for $\mathrm{GO}$ patients in clinical practice.

\section{REFERENCES}

1. Noth D, Gebauer M, Müller B, Bürgi U, Diem P. Graves' ophthalmopathy: natural history and treatment outcomes. Swiss Med Wkly. 2001;131:603-

2. Weetman AP. Grave's disease 1835-2002. Horm Res. 2003; 59 Suppl $1: 114-8$

3. Bartalena L, Baldeschi L, Dickinson AJ, Eckstein A, Kendall-Taylor P, Marcocci C et al. Consensus statement of the European Group on Graves' orbitopathy (EUGOGO) on management of Graves' orbitopathy. Thyroid. 2008;18:333-46.

4. McKinnon SG, Gentry LR. Systemic diseases involving the orbit. Semin Ultrasound CT MR. 1998; 19:292-308.

5. Monteiro ML, Gonçalves AC, Silva CT, Moura JP, Ribeiro CS Gebrim EM .Diagnostic ability of Barrett's index to detect dysthyroid optic neuropathy using multidetector computed tomography. Clinics. 2008;63:301-6.

6. Mouritz MP, Koornnef L, Wiersinga WM, Prummel MF, Berghout A, Gaag RVD. Clinical criteria for the assessment of disease activity in Graves' ophthalmopathy: a novel approach. Br J Ophthalmol. 1989;73:639-44.

7. Werner SC. Modification of the classification of the eye changes of Graves' disease: recommendations of the Ad Hoc Committee of the American Thyroid Association. J Clin Endocrinol Metab. 1977;44:203-4.
8. Prummel MF, Bakker A, Wiersinga WM, Baldeschi L, Mourits MP, Kendall-Taylor P et al. Multi-center study on the characteristics and treatment strategies of patients with Graves' orbitopathy: the first European Group on Graves' Orbitopathy experience. Eur J Endocrinol. 2003;148:491-5

9. Gorman CA. The measurement of change in Graves' ophthalmopathy. Thyroid. 1998; 8:539-43.

10. Edwards DT, Bartley GB, Hodge DO, Gorman CA, Bradley EA. Reliability of a Photographic Technique and Comparison with a Clinical Technique. Ophthalmology 2004;111:1029-34.

11. Cruz AA, Coelho RP, Baccega A, Lucchezi MC, Souza AD, Ruiz EE. Digital image processing measurement of the upper eyelid contour in Graves' disease and congenital blepharoptosis. Ophthalmology. $1998 ; 105: 913-8$

12. Miot HA, Paixão MP, Paschoal FM. Fundamentos da fotografia digital em Dermatologia. An Bras Dermatol. 2006;81:174-80.

13. Abramoff MD, Magalhaes PJ, Ram SJ. Image Processing with ImageJ Biophotonics International. 2004;11:36-42.

14. Miot HA, Pivotto DR, Jorge EN, Mazeto GMFS. Evaluation of oculometric parameters by facial digital photography: use of iris diameter as a reference. Arq Bras Oftalmol. 2008;71:679-83. 
15. Ayres M, Ayres Jr M, Ayres DL, dos Santos AS. Bioestat: 3.0 aplicações estatísticas nas áreas das ciências biológicas e médicas. Belém: Sociedade Civil Mamirauá MCT - CNPq Conservation International. 2003.

16. Huang K, Murphy RF. From quantitative microscopy to automated image understanding. Journal of Biomedical Optics. 2004;9:893-912.

17. Wolf DE, Samarasekera C, Swedlow JR. Quantitative analysis of digital microscope images. Methods Cell Biol. 2007;81:365-96.

18. Costa P, Saraiva FP, Pereira IC, Matayoshi S. Morphometric analysis of eyelid fissure in patients with eyelid retraction in acute stage of disthyroid orbitopathy after treatment with botulinum toxin type A. Arq Bras Oftalmol. 2008;71:480-5.
19. Boboridis K, Assi A, Indar A, et al. Repeatability and reproducibility of upper eyelid measurements. Br J Ophthalmol. 2001;85:99-101.

20. Matai O, Lavezzo MM, Schellini SA, Padovani CR, Padovani CR. Evaluation of eyebrow position using angular measures. Arq Bras Oftalmol. 2007;70:41-4.

21. Rubin PA. Eyelid position measurement. Ophthalmology. 2005;112:5245 . 
